\title{
Molecular Typing and Presence of Genetic Markers Among Strains of Banana Finger-Tip Rot Pathogen, Burkholderia cenocepacia, in Taiwan
}

\author{
Yung-An Lee and Chih-Wen Chan
}

Department of Life Science, Fu Jen Catholic University, Hsin Chuang, Taipei County, Taiwan 24205, Republic of China. Accepted for publication 21 August 2006.

\begin{abstract}
Lee, Y.-A., and Chan, C.-W. 2007. Molecular typing and presence of genetic markers among strains of banana finger-tip rot pathogen, Burkholderia cenocepacia, in Taiwan. Phytopathology 97:195-201.

Burkholderia cenocepacia (genomovar III of B. cepacia complex), the causal agent of banana finger-tip rot, is a common plant-associated bacterium but also an important opportunistic pathogen of humans. To better understand the nature of B. cenocepacia from banana, the genetic variation among $B$. cenocepacia isolates from various banana-growing regions in southern Taiwan was examined. Forty-four serial isolates recovered from diseased banana stigmata from three banana-growing regions during the periods ranging from 2002 to 2004 were investigated. All B. cenocepacia isolates picked from quinate-yeast extract tetracycline-polymyxin semiselective medium could cause onion maceration and were polymerase chain reaction (PCR) positive for $b c s c V$, which is a type III secretion gene present in all members of the B. cepacia complex except $B$. cepacia (formerly genomovar I). Genetic diversity was assessed using recA PCR

restriction fragment length polymorphism, recA nucleotide sequence analysis, and pulsed-field gel electrophoresis assays. The assays revealed the genetic variability among the isolates and also allowed us to trace the relationship among isolates. The isolates all were assigned to genomovar III and consisted of two groups, $\mathrm{A}$ and $\mathrm{B}$, which corresponded to recA lineage IIIA and IIIB. The group B strains were separated into B1 and B2 subgroups and the B1 strains were further divided into distinct lineages. The B1 strains were the most frequently detected and occurred in all regions tested. There was no significant difference between strains from each subgroup in the virulence on banana fingers of $\mathrm{cv}$. Cavendish. PCR assays were further used to determine whether $B$. cenocepacia from banana contained the cable pilus subunit gene (cblA), IS1356, and B. cepacia epidemic strain marker (BCESM), which are DNA markers associated with epidemic B. cepacia clinic strains. The results indicated that $c b l A$ and IS1356 were absent but the BCESM was found in all isolates. The present study revealed that banana is a natural reservoir of genetically diversified B. cenocepacia strains.
\end{abstract}

Banana finger-tip rot disease affects banana fruit fingers of cultivars in the AAA genomic group. Symptoms of the disease include small and externally distorted shape of affected fingers and brown discoloration of pulp. The disease was distributed in commercial fields in Pingtung and Kaohsiung Counties, Taiwan. The pathogen was isolated in a previous study and identified as Burkholderia cepacia (11). The genomovar status of the banana finger-tip rot pathogen within the B. cepacia complex was identified by determining its polymerase chain reaction restriction fragment length polymorphism (PCR-RFLP) pattern and by sequence analysis of the $16 \mathrm{~S}$ ribosomal (r)DNA and recA. The results indicated that the banana finger-tip rot pathogen belongs to genomovar III in the B. cepacia complex (10), which is proposed as a new species, $B$. cenocepacia (32).

The $B$. cepacia complex is a very diverse group of bacteria (33), consisting of nine genomovars that recently were elevated to species status $(5,31,32,34,35)$. In addition, the ability of $B$. cepacia to cause disease is not limited to plant hosts, because this bacterium also is an important opportunistic respiratory pathogen, particularly in patients with cystic fibrosis (CF) $(8,9,12)$ and chronic granulomatous disease (26). Among these genomovars, B. cenocepacia (genomovar III) is by far the most prevalent genomovar isolated from patients with CF (14). Strains of B. cenocepacia are divided into two lineages, III-A and III-B, based on sequence variations of $\operatorname{rec} A(14,15)$. The prevalence of each lineage of $B$. cenocepacia varies between different $\mathrm{CF}$

Corresponding author: Y.-A. Lee; E-mail address: bio1007@ mails.fju.edu.tw

DOI: 10.1094/PHYTO-97-2-0195

(C) 2007 The American Phytopathological Society populations $(1,13,14)$. Because $B$. cenocepacia causes banana finger-tip rot, banana may be a natural habitat and an important environmental source of $B$. cenocepacia. However, there is considerable genetic variation among strains within $B$. cenocepacia (2), and strains of banana finger-tip rot pathogen may not be associated with clinical strains.

To understand the nature of $B$. cenocepacia from banana, the genetic variation among B. cenocepacia isolates from banana should be determined. In this article, we report the use of a semiselective medium and PCR-based tests to isolate and identify B. cenocepacia isolates from banana plants from three bananagrowing regions in southern Taiwan. The genetic variability of the isolates was determined by PCR-RFLP analysis of recA and pulsed-field gel electrophoresis (PFGE). We also report results concerning the distribution of genetic markers associated with the cable pilus subunit gene (cblA) (21), IS1356 (30), and the B. cepacia epidemic strain marker (BCESM) (17), which are associated with epidemic strains isolated from patients with cystic fibrosis.

\section{MATERIALS AND METHODS}

Isolation method, bacterial strains, and culture conditions. A quinate-yeast extract tetracycline-polymyxin (QY-TP) semiselective medium (10) was used to isolate the finger-tip rot pathogen, B. cenocepacia. One liter of QY-TP medium contained $5.0 \mathrm{~g}$ of quinic acid, $5.0 \mathrm{~g}$ of yeast extract, $1.5 \mathrm{~g}$ of $\mathrm{K}_{2} \mathrm{HPO}_{4}$, $1.5 \mathrm{~g}$ of $\mathrm{MgSO}_{4} \cdot 7 \mathrm{H}_{2} \mathrm{O}, 1.0 \mathrm{~g}$ of $\left(\mathrm{NH}_{4}\right)_{2} \mathrm{SO}_{4}$, and $15.0 \mathrm{~g}$ of agar. The medium was adjusted to $\mathrm{pH} 7.2$ to 7.5 with $10 \mathrm{~N} \mathrm{NaOH}$ and was autoclaved for $10 \mathrm{~min}$ at $121^{\circ} \mathrm{C}$. Tetracycline (Sigma-Aldrich, St. Louis) and polymyxin (Sigma-Aldrich) stock solutions were prepared separately and added to the medium after autoclaving to 
give final concentrations of $50 \mathrm{mg} /$ liter and 600,000 U/liter, respectively. Bacteria were isolated during 2002-04 from diseased banana fruit fingers from three banana cultivation areas (Jiouru, Gaoshu, and Shanlin) in Kaohsiung and Pingtung Counties in southern Taiwan.

Parts of the discolored pulp within the banana fingers were removed and immersed in sterile water for $10 \mathrm{~min}$. One loopfu1 of the extract from each banana finger was streaked onto QY-TP semiselective medium and plates were incubated at $28^{\circ} \mathrm{C}$ for 2 days. After isolation by QY-TP medium, B. cenocepacia was routinely cultured on Luria-Bertani agar (LA) or in broth medium (23) at $28^{\circ} \mathrm{C}$. The collection of $B$. cenocepacia isolates used in this study is shown in Table 1.

Biochemical, physiological, and onion maceration tests. The oxidase test and acid production from carbohydrates were conducted according to Schaad et al. (24). The API 20E and 20NE system tests (BioMerieux Vitek Inc., Hazelwood, MO) were used for biochemical tests of lysine decarboxylase, ornithine decarboxylase, and hydrolysis of gelatin and esculin. For the onion maceration test, onion bulbs were inoculated by pricking them with a $10-\mu$ l pipette tip and then adding $5 \mu$ l of bacterial suspension of B. cenocepacia at $10^{7} \mathrm{CFU} / \mathrm{ml}$. The bulbs were incubated at $28^{\circ} \mathrm{C}$.

General DNA manipulations. Mini-scale preparations of Escherichia coli plasmid DNA, total genomic DNA isolation of $B$. cenocepacia, restriction endonuclease treatments, DNA ligation, transformation, and agarose gel electrophoresis were done as described by Sambrook et al. (23). For cloning and sequencing of PCR-amplified DNA fragments, the DNA fragments were ligated into pGEM-T Easy vectors (Promega Corp. Madison, WI). The E. coli DH5 $\alpha$ strain was used for gene cloning and was cultured on LA medium at $37^{\circ} \mathrm{C}$. Ampicillin $(50 \mu \mathrm{g} / \mathrm{ml})$ was added as necessary to maintain selection of the resistance marker in the pGEM-T Easy vectors. PCR-amplified DNA fragments which were used as probes were labeled with digoxigenin-11-dUTP (DIG) using a PCR DIG probe synthesis kit (Boehringer Mannheim Biochemicals, Indianapolis, IN). Prehybridization, hybridization, and washing for Southern hybridization with DIG-labeled probes were performed at $68^{\circ} \mathrm{C}$ according to the manufacturer's protocol. Double-stranded sequencing was performed using a 373A automated DNA sequencer and an ABI Prism DNA Sequencing kit (Applied Biosystems, Foster City, CA) with standard universal T7 and SP6 primers.

The recA phylogenetic tree was constructed using the method described by Mahenthiralingam et al. (15). Multiple sequence alignments were performed using CLUSTAL W (29) and distance analyses were performed using the phylip package in the dnadist program (6). Divergence between two sequences was estimated using Jukes-Cantor distance matrices and phylogenetic tree was inferred using the neighbor-joining method (20).

PCR-RFLP analysis of $16 \mathrm{~S}$ rDNA and $\mathbf{r e c A}$. The genomovar status of the pathogens in the B. cepacia complex was determined by PCR-RFLP pattern and sequence analysis of $16 \mathrm{~S}$ rDNA and recA as described by Mahenthiralingam et al. (15). 16S rDNA and recA gene fragments were amplified by PCR with UN12/UN15 and BCR1/BCR2 primer pairs, respectively. Colonies of B. cenocepacia taken from the LA medium were suspended in $50 \mu \mathrm{l}$ of sterile distilled water. The bacterial suspension was incubated for $10 \mathrm{~min}$ at $100^{\circ} \mathrm{C}$ for cell lysis and was maintained at $4^{\circ} \mathrm{C}$ before use. PCR amplifications were performed with a GeneAmp PCR system 2400 (Perkin-Elmer Corporation, Norway, $\mathrm{CT}$ ) in a $50-\mu \mathrm{l}$ reaction mixture containing $1 \mu \mathrm{l}$ of cell lysate, $0.2 \mu \mathrm{M}$ each primer, $0.4 \mathrm{mM}$ each deoxynucleoside triphosphate, $1 \times$ reaction buffer $\left(1.5 \mathrm{mM} \mathrm{MgCl}_{2}, 50 \mathrm{mM} \mathrm{KCl}, 0.1 \%\right.$ Triton X100, 10 mM Tris-HCl; $\mathrm{pH} 8.8$ ), 4\% dimethyl sulfoxide (DMSO) (J. T. Baker, Phillipsburg, NJ), and 4.0 U of Taq DNA polymerase (DyNAzyme II, Finnzymes Oy, Finland) by using the following program: 1 cycle of denaturation for $1 \mathrm{~min}$ at $94^{\circ} \mathrm{C} ; 35$ cycles consisting of denaturation at $94^{\circ} \mathrm{C}$ for $30 \mathrm{~s}$, annealing at $60^{\circ} \mathrm{C}$ for $30 \mathrm{~s}$, and extension at $72^{\circ} \mathrm{C}$ for $45 \mathrm{~s}$; followed by a final extension (hold) at $72^{\circ} \mathrm{C}$ for $2 \mathrm{~min}$. Reactions were stored at $4^{\circ} \mathrm{C}$ until they were used for analysis. Amplified DNA was detected by electrophoresis in $0.8 \%$ agarose (agarose I; Amresco Inc., Solon, $\mathrm{OH}$ ) in $1 \times$ Tris-acetate EDTA (TAE) buffer (40 mM Tris-acetate, 1 mM EDTA, pH 8.0).

For RFLP analysis, PCR-amplified DNA fragments were recovered from agarose by using the GFX PCR DNA and gel band purification kit (Amersham Pharmacia Biotech. Inc., Piscataway, NJ). They then were digested with DdeI, HaeIII, or MnlI (New England Biolabs, Inc., Beverly, MA.), and analyzed by $2.5 \%$ agarose gel electrophoresis.

PFGE of total genomic DNA. B. cenocepacia cells were grown for $24 \mathrm{~h}$ on tryptone soya agar (1.5\% tryptone, $0.5 \%$ soytone, $0.5 \% \mathrm{NaCl}$, and $1.5 \%$ agar) at $28^{\circ} \mathrm{C}$. Genomic DNA for PFGE was prepared in agarose plugs using the method described by Ribot et al. (19) with slight modifications. The cells were suspended in a polystyrene round-bottomed tube (Falcon, 17 by $100 \mathrm{~mm}$; Becton Dickinson, Franklin Lakes, NJ) containing cell suspension buffer (100 mM Tris, $100 \mathrm{mM}$ EDTA, $\mathrm{pH}$ 8.0) to an optical density of 0.8 to 1.0 measured with a

TABLE 1. Grouping, polymerase chain reaction restriction fragment length polymorphism (PCR-RFLP), pulsed-field gel electrophoresis (PFGE), and PCR analyses of Burkholderia cenocepacia isolates on banana

\begin{tabular}{|c|c|c|c|c|c|c|c|c|c|}
\hline \multirow[b]{2}{*}{ Group $^{a}$} & \multirow[b]{2}{*}{ Isolate $^{b}$} & \multirow[b]{2}{*}{ Location } & \multirow[b]{2}{*}{ Year } & \multirow[b]{2}{*}{$16 \mathrm{~S} \mathrm{rDNA}^{\mathrm{c}}$} & \multicolumn{2}{|c|}{ recA-RFLP } & \multicolumn{3}{|c|}{ PFGE } \\
\hline & & & & & $M n l \mathrm{I}^{\mathrm{d}}$ & Hae III ${ }^{\mathrm{d}}$ & $P a c \mathrm{I}^{\mathrm{e}}$ & $X b a \mathrm{I}^{\mathrm{e}}$ & $S p e \mathrm{I}^{\mathrm{d}}$ \\
\hline A & $\mathrm{B} 5, \mathrm{~B} 9, \mathrm{~B} 10, \mathrm{~B} 11$ & Jiouru, Pingtung & 2002 & 2 & $\mathrm{f}$ & G & 1 & 1 & 1 \\
\hline \multicolumn{10}{|l|}{ B } \\
\hline \multicolumn{10}{|l|}{ B1 } \\
\hline \multirow[t]{4}{*}{ B 1-1 } & CT1, CA2, CB2, CC2, & Jiouru, Pingtung & 2002 & 2 & $\mathrm{i}$ & $\mathrm{H}$ & 2 & 2 & 2 \\
\hline & DL21, DQ23, DQ24, DQ31 & Jiouru, Pingtung & 2003 & 2 & $\mathrm{i}$ & $\mathrm{H}$ & 2 & 2 & 2 \\
\hline & FL61, FL62, FL63, FL71 & Gaoshu, Pingtung & 2003 & 2 & $\mathrm{i}$ & $\mathrm{H}$ & 2 & 2 & 2 \\
\hline & $\mathrm{EC} 11, \mathrm{EC} 12, \mathrm{EC} 13, \mathrm{EC} 21$ & Jiouru, Pingtung & 2004 & 2 & $\mathrm{i}$ & $\mathrm{H}$ & 2 & 2 & 2 \\
\hline \multicolumn{10}{|l|}{ B $1-2$} \\
\hline \multirow[t]{4}{*}{ B1-2-1 } & GQ31, GQ41, GQ52, GQ61 & Jiouru, Pingtung & 2003 & 2 & $\mathrm{i}$ & $\mathrm{J}$ & 2 & 3 & 3 \\
\hline & GQ7T, GQ8T, GQ9T, GQ10T & Jiouru, Pingtung & 2004 & 2 & $\mathrm{i}$ & $\mathrm{J}$ & 2 & 3 & 3 \\
\hline & FL11, FL21, FL51, FL61 & Gaoshu, Pingtung & 2004 & 2 & $\mathrm{i}$ & $\mathrm{J}$ & 2 & 3 & 3 \\
\hline & LQ11, KQ11, KQ12, KQ21 & Shanlin, Kaohsiung & 2004 & 2 & $\mathrm{i}$ & $\mathrm{J}$ & 2 & 3 & 3 \\
\hline B1-2-2 & HQ11, H2Q11, H2Q21, H3Q1 & Gaoshu, Pingtung & 2004 & 2 & $\mathrm{i}$ & $\mathrm{J}$ & 2 & 3 & 4 \\
\hline B2 & MQ41, MQ42, MQ43, MQ51 & Jiouru, Pingtung & 2004 & 2 & $\mathrm{~h}$ & I & 3 & 4 & 5 \\
\hline
\end{tabular}

a Grouping based on recA-RFLP and PFGE pattern analysis in this study. Groups A and B correspond to recA lineage IIIA and IIIB.

${ }^{\mathrm{b}}$ Each isolate was from one diseased banana finger of different banana plants.

c $16 \mathrm{~S}$ ribosomal (r)DNA DdeI-RFLP; RFLP pattern designations based on Mahenthiralingam et al. (16).

${ }^{\mathrm{d}}$ RFLP pattern designations based on Mahenthiralingam et al. (16).

e PFGE pattern type assigned in this study. 
MicroScan Turbidity meter (Dade Behring Inc., West Sacramento, CA). Bacterial suspensions were mixed with $20 \mu \mathrm{l}$ of proteinase $\mathrm{K}$ $(20 \mathrm{mg} / \mathrm{ml}$; Amresco Inc., Solon, $\mathrm{OH})$ and the same volume of 1.0\% SeaKem Gold agarose (Cambrex Bio Science Rockland, Inc., Rockland, ME) in Tris-EDTA (TE) buffer (10 mM Tris, $1 \mathrm{mM}$ EDTA, $\mathrm{pH}$ 8.0), and were pipetted into a plastic mold. The hardened agarose plugs were immersed in cell lysis buffer (50 mM Tris, $50 \mathrm{mM}$ EDTA, 1\% N-lauroylsarcosine, proteinase $\mathrm{K}$ at $0.1 \mathrm{mg} / \mathrm{ml}, \mathrm{pH} 8.0$ ) for $2 \mathrm{~h}$ at $56^{\circ} \mathrm{C}$. After lysis, the plugs were washed ( $15 \mathrm{~min}$ per wash) at $56^{\circ} \mathrm{C}$ two times with sterile double-distilled water and four times with TE buffer in a shaking water bath. Chromosomal DNA plugs were incubated with PacI, $X b a \mathrm{I}$, and SpeI (New England Biolabs) at $37^{\circ} \mathrm{C}$ for $2 \mathrm{~h}$. Restriction fragments were separated by PFGE through $1.0 \%$ SeaKem Gold agarose in $0.5 \times$ Tris-borate EDTA (TBE) buffer (45 mM Tris-borate, $1 \mathrm{mM}$ EDTA, $\mathrm{pH}$ 8.0) containing $100 \mathrm{mM}$ thiourea with a Rotaphor apparatus (Biometra, Göttingen, Germany) using $0.5 \times \mathrm{TBE}$ as a running buffer. PFGE was performed using a field strength of $200 \mathrm{~V}$ for $22 \mathrm{~h}$ at $14^{\circ} \mathrm{C}$ with the pulse time being linearly increased from 2 to $54 \mathrm{~s}$. A fixed reorientation angle of $120^{\circ}$ was used. After the electrophoresis run was completed, the gels were stained with ethidium bromide solution $(0.5 \mu \mathrm{g} / \mathrm{ml})$ and destained in water, and the band pattern was observed under UV illumination.

Virulence of $\boldsymbol{B}$. cenocepacia strains on banana. The banana used for inoculation was Tai-Chiao no. 3 of cv. Cavendish at young fruit stage, 6 to 7 months after planting. Bacterial suspensions $\left(10^{8} \mathrm{CFU} / \mathrm{ml}\right)$ of $B$. cenocepacia were injected through the center of the stigma and the fingers were enclosed in a plastic bag to maintain high humidity. Five banana fingers at a length of 15 to $20 \mathrm{~cm}$ were inoculated for each strain. Control plants were inoculated with sterile distilled water. The experiment was repeated three times. Disease ratings were determined 14 days after inoculations as follows: $0=$ no visible symptoms, $1=0.5$ to $1 \mathrm{~cm}$ of the internal pulp (starting from the inoculated position) became rotted (brown discoloration), $2=1$ to $2.5 \mathrm{~cm}$ of the internal pulp rotted. The level of disease severity for each strain was expressed by a disease rating index $(I)$ which was calculated according to the formula $I=\Sigma\left(D_{i} n_{i}\right) /(2 N)$, where $D_{i}=$ disease rating, $i=0$ to $2, n_{i}=$ the number of banana fingers showing the rating $i$, and $N=$ total banana finger number. A one-way analysis of variance test was used to determine the statistical significance of differences in the results. A probability value of $P \leq 0.05$ was considered to be statistically significant.

PCR assays of $B$. cenocepacia from banana. The bcscV-1F (5'-GACTG GCAGC GGTTG TTTTC CG-3') and CP11 (5'-GCCCT TCACG AACTT CATC-3') primers were designed from the nucleotide sequence of $b c s c V$ (GenBank accession no. AY028431) for the differentiation of B. cepacia genomovar I and III strains (18). The bcscV-1F and CP11 primers delineated a 618-bp DNA fragment. To determine whether B. cenocepacia from banana contains the cblA (21), IS1356 (30), and BCESM (17), which are DNA markers associated with epidemic B. cepacia strains from CF patients, PCR assays were carried out using the following primers: Bc-cblA-F (5'-CCAAA GGACT AACCC ATGCT G-3')/Bc-cblA-R (5'-ACGCG ATGTC CATCA CATAC AG-3') for cblA, IS1356-A (5'-GGCCC TGAAG AAGGC GATAT-3')/IS1356-B (5'-TCCGG CGACA CCTCG ATGCC- $\left.3^{\prime}\right)$ for IS 1356 , and BCESM 1 (5'-CCACG GACGT GACTA ACA-3')/BCESM 2 (5'-CGTCC ATCCG AACAC GAT$3^{\prime}$ ) for BCESM. The primer sets delineated 722-, 327-, and 1.4-kb DNA fragments, respectively. PCR amplifications were performed using the protocol described above.

Nucleotide sequence accession number. The recA partial sequences of B. cenocepacia strains B9, CA2, GQ52, and MQ41 have been assigned the GenBank accession nos. AY598028, DQ664181, DQ664182, and DQ664183, respectively. The BCESM sequence of B. cenocepacia strain B9 was assigned DQ267754.

\section{RESULTS}

Isolation and identification of $\boldsymbol{B}$. cenocepacia isolates from banana. Forty-four isolates were obtained from the stigmata of diseased banana plants cultivated in fields located in southern Taiwan. QY-TP semiselective medium was used to isolate B. cenocepacia, and white, shiny, and mucoid colonies were chosen for further characterization. All isolates chosen were positive for oxidase, lysine decarboxylase, and ornithine decarboxylase. They hydrolyzed gelatin and esculin, and produced acids by utilizing sucrose, maltose, D-mannitol, D-sorbitol, and dulcitol, but not melibiose and rhamnose. The isolates could cause onion maceration and were PCR positive for $b c s c V$. Based on these results, all 44 isolates were identified as B. cenocepacia.

Determination of genomovar status and genetic diversity by PCR-RFLP of $B$. cenocepacia isolates from banana. The genomovar status and genetic variability of the $B$. cenocepacia isolates from banana were determined by PCR-RFLP analysis of $16 \mathrm{~S}$ rDNA and recA as described in Mahenthiralingam et al. (15). PCR amplification using UN12/UN15 and BCR1/BCR2 primer sets resulted in a 1,020-bp $16 \mathrm{~S}$ rDNA fragment and a 1,040-bp recA gene fragment, respectively, for all $44 \mathrm{~B}$. cenocepacia isolates. Restriction analyses of the amplified fragments then were performed using DdeI for the 16S rDNA fragment and HaeIII and $M n l I$ for the $r e c A$ gene fragment. Only one $16 \mathrm{~S}$ rDNA RFLP pattern was found for all the B. cenocepacia isolates tested. However, digestion of the recA amplicon with the endonucleases $M n l \mathrm{I}$ or HaeIII generated a number of patterns revealing considerable genetic variability (Fig. 1). The recA RFLP patterns were compared with those from the previously published representative panel of the B. cepacia complex (15), where MnlI RFLP patterns designated a to i and HaeIII RFLP patterns A to J were reported. Three distinct $M n l I$ RFLP patterns were found among the 44 isolates, which corresponded to patterns $\mathrm{f}, \mathrm{h}$, and $\mathrm{i}$ (Table 1). Strains with pattern $\mathrm{f}$ belong to genomovar III-A, and those with patterns $h$ and $i$ belong to genomovar III-B (15). RFLP analysis with HaeIII revealed four patterns which correspond to patterns G, H, I, and J. Strains with pattern G belong to genomovar III-A, and those with patterns $\mathrm{H}$, I, and $\mathrm{J}$ belong to genomovar III-B (15). The representative results are shown in Figure 1.

To further confirm the results from the PCR-RFLP analyses of amplified $r e c A$, a phylogenetic relationship among $r e c A$ genes of B. cepacia complex was determined. The recA phylogenetic tree of $B$. cepacia complex has been constructed by Mahenthiralingam et al. (15); therefore, the same method was used to reconstruct the tree of B. cepacia complex containing banana finger-tip rot pathogen strains. The nucleotide sequences of $\mathrm{rec} A$ genes of five strains of banana finger-tip rot pathogen, B. cenocepacia B9, CA2, GQ52, H2Q11, and MQ41, were determined. Because the recA sequences of strains GQ52 and H2Q11 were identical, only that of strain GQ52 was used for phylogenetic analysis. The recA sequences of strains B9, CA2, GQ52, and MQ41 were aligned with available $r e c A$ sequences of representative strains of $B$. cepacia genomovar I-VI for the construction of phylogenetic tree. The resulting phylogenetic tree is shown in Figure 2. All previously determined genomovars (I, II, IIIA, IIIB, IV, V, and VI) formed distinct arms within the tree. The sequence of B9 strain aligned closely with recA group IIIA of genomovar III strain C5424, but those of strains CA2, GQ52, and MQ41 were clustered together and aligned closely with recA group IIIB of genomovar III strain C1394. Based on the PCR-RFLP analysis of 16S rDNA and $r e c A$, all isolates of banana finger-tip rot pathogen were determined as B. cenocepacia (B. cepacia genomovar III) (32), and contained two groups, $\mathrm{A}$ and $\mathrm{B}$, corresponding to recA lineage IIIA and IIIB. The group B strains contained two distinct $M n l$ I RFLP patterns (B1 and B2), and the B1 strains were further divided into B1-1 and B1-2 by HaeIII recA PCR-RFLP pattern analysis (Fig. 1). 
PFGE analysis of $B$. cenocepacia isolates from banana. B. cenocepacia has a high $\mathrm{G}+\mathrm{C}$ content (66 to 68\%) (32); therefore, we chose the restriction endonucleases $\mathrm{PacI}$ (recognition site 5'-TTAATTAA-3'), XbaI (5'-TCTAGA-3'), and SpeI (5'-ACTAGT-3'), which recognize an AT-rich nucleotide sequence, to produce genomic DNA restriction fragments. The PacI restriction digest produced fewer fragments than the $\mathrm{XbaI}$ and SpeI digests. With $\mathrm{PacI}$ digestion, group A (recA lineage IIIA) strains produced only one pattern (A), but group B (recA lineage IIIB) strains produced two distinguishable patterns (B1 and B2). Four distinct patterns were produced with $X b a I$ digestion. The strains with the B1 pattern after PacI digestion were further divided into two types (B1-1 and B1-2) by XbaI digestion.

Five patterns were produced with SpeI digestion. The strains with the B1-2 patterns after $X b a \mathrm{I}$ digestion were further separated into two types (B1-2-1 and B1-2-2) by digestion with SpeI. The grouping of B. cenocepacia strains based on the PacI and $\mathrm{Xba \textrm {I }}$ PFGE patterns was consistent with that of the MnlI and HaeIII recA PCR-RFLP patterns, respectively (Figs. 1 and 3). Representative results of PFGE are shown in Figure 3. All B. cenocepacia isolates tested were analyzed at least three times, and the reproducibility of the PFGE patterns was confirmed for each strain.

Virulence of $B$. cenocepacia strains on banana. B. cenocepacia strains B9, CA2, GQ52, H2Q11, and MQ41, which represent different recA-RFLP and PFGE patterns, were chosen for pathogenicity analysis. Most $(80 \%)$ of the wound inoculations of each strain were successful and typical symptoms appeared in 14 days. The average of disease rating index of these five strains ranged from 0.3 to 0.4 . The statistical analysis revealed no significant difference between strains in the virulence.

PCR and Southern hybridization analysis of $\boldsymbol{B}$. cenocepacia isolates from banana. B. cenocepacia isolates from banana were tested for the presence of DNA markers associated with epidemic B. cepacia strains from CF patients, such as cblA (21), IS1356 (30), and BCESM (17). PCR assays were carried out on all 44 isolates listed in Table 1. No amplification using the primer sets for cblA and IS1356 was observed with the B. cenocepacia isolates from banana. The same $c b l A$ and IS1356 primer sets amplified 722- and 327-bp DNA fragments from B. cenocepacia LMG18826 and LMG18863, respectively, which are clinical strains of genomovar III obtained from Belgian Coordinated Collections of Microorganisms. However, PCR amplification using the BCESM primers BCESM 1 and BCESM 2 produced a 1.4-kb DNA fragment for all the B. cenocepacia isolates from banana (Fig. 4A). The BCESM was reported to be specifically associated with epidemic CF strains (17). The amplified BCESM DNA fragment of B. cenocepacia B9 was cloned, sequenced, and compared with the nucleotide sequence of BCESM in GenBank (U81966). Both nucleotide sequences share $94 \%$ identity. The BCESM probe hybridized to a $9.5-\mathrm{kb}$ EcoRI fragment in all B. cenocepacia isolates tested (Fig. 4B).

\section{DISCUSSION}

To better understand the genetic diversity of B. cenocepacia from banana, the strains were isolated from the stigmata of diseased bananas using QY-TP semiselective medium. In addition to physiological and biochemical tests, our strategy to rapidly determine the identity of $B$. cenocepacia was to examine the isolates by onion maceration and by using a PCR assay for $b c s c V$. In the B. cepacia complex, both B. cenocepacia (genomovar III) and $B$. cepacia (genomovar I) can cause onion maceration (3), but $b c s c V$, which is a type III secretion gene, is present in $B$. cenocepacia and absent in B. cepacia (18). All of the white, shiny, and mucoid colonies picked from QY-TP semiselective medium could cause onion maceration and were PCR positive for $b c s c V$, suggesting that all the isolates were B. cenocepacia. The $16 \mathrm{~S}$ rDNA and recA PCR-RFLP tests further confirmed that all the B. cenocepacia isolates from banana belonged to genomovar III of the $B$. cepacia complex, and contained recA IIIA and IIIB lineages (group A and B).

The grouping of $B$. cenocepacia strains in Taiwan was consistent between the recA PCR-RFLP and PFGE pattern analyses (Figs. 1 and 3). Although the sample sizes used in this study were not adequate to draw definite conclusions about the genetic variability, distribution, or even evolution of $B$. cenocepacia in Taiwan, the results reported here emphasized that, using different restriction enzymes, the recA PCR-RFLP and PFGE tests were efficient in revealing genetic variability in the $B$. cenocepacia population, and allowed for strain identification to track the relationship between strains. The results in this study indicated that B. cenocepacia from banana contained group A and B strains in Taiwan, and the group B strains, which contain four lineages (B11, B1-2-1, B1-2-2, and B2), were dominant and more diverse than
A

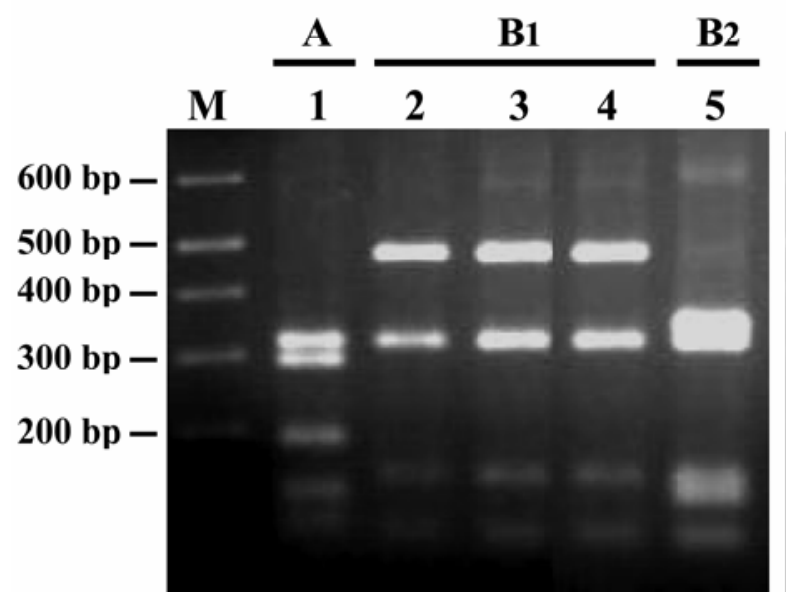

B

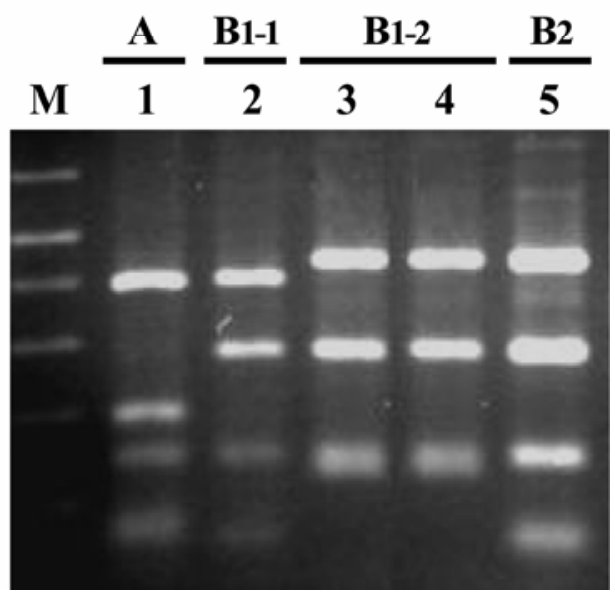

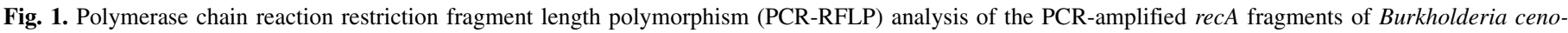

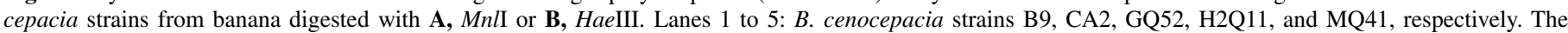

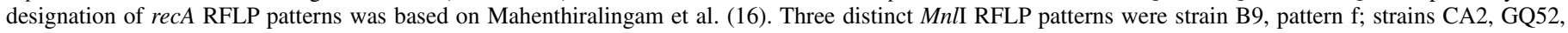

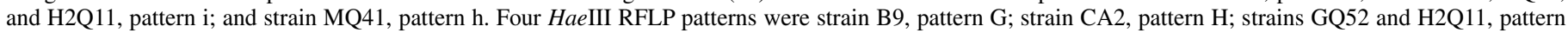

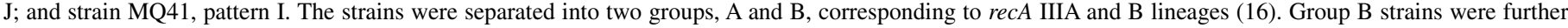

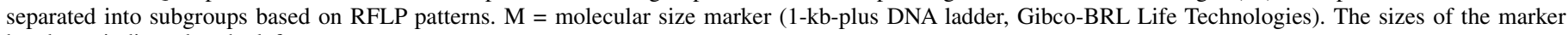
bands are indicated to the left. 
the group A strains. The group B strains were detected in all three banana-growing regions of Taiwan compared with one region (Jiouru) for group A strains. This suggests that the group B strains might have been introduced as a banana pathogen before group A strains, or are highly transmissible and particularly well adapted to survival on banana plants in the regions.

The ability of B. cenocepacia to cause disease is not limited to plant hosts, because the bacterium is also an important opportunistic pathogen of humans, causing devastating infections in patients with $\mathrm{CF}(8,12)$. In CF patients, the high prevalence of $B$. cenocepacia isolates is a major concern because $B$. cenocepacia infections are more likely to be chronic and patients with B. cenocepacia infections face the highest mortality (14). Hospitals may acquire $B$. cenocepacia from environmental sources. Nevertheless, because there is considerable genetic variation among B. cenocepacia strains (2), B. cenocepacia strains from banana may not be associated with clinical strains that cause human disease. Because they are not available in Taiwan, clinical strains of $B$. cenocepacia were not tested for banana pathogenicity; however, results of such an experiment would be of interest. However, analysis of PFGE profiles is one way to understand the relationship between clinical and environmental strains of $B$. cenocepacia $(25,27)$. Using PFGE profile analysis, Butler et al. (4) did not find any relationship between British clinical isolates and natural environmental isolates that were recovered from soil, water, or vegetation. Because PFGE profiles of clinical strains in Taiwan were not available, we compared the profiles of B. cenocepacia strains from banana with those of 30 well-characterized clinical strains of the B. cepacia complex (16). None of the strains from banana matched those PFGE profiles.

Several genetic markers have been shown to be associated with epidemic B. cepacia strains from CF patients. These include the cblA gene, which encodes a pilin that binds to CF mucin and, thus, is likely to promote transmission in the $\mathrm{CF}$ population $(7,21$, 22,28); IS 1356, which, in association with the element IS402, also may serve as a genetic marker for the epidemic B. cepacia strain type with a cable pilus (30); and the BCESM, which is associated with $B$. cepacia strain types infecting multiple $\mathrm{CF}$ patients (17). These markers are absent in some epidemic strains, indicating that they may not be reliable indicators of transmissibility (13). Nonetheless, we tested the existence of these markers in B. cenocepacia strains from banana using PCR assays.

All B. cenocepacia strains tested from banana were PCR negative for the cblA gene and IS1356, but positive for BCESM. The BCESM probe also hybridized to a 9.5-kb EcoRI fragment in the group A and B strains tested, indicating that the group A and B strains might originate from a common ancestor. The presence of BCESM in all the B. cenocepacia strains from the banana plants examined in this study is in contrast to the results of Mahenthiralingam et al. (17), whose studies highlighted the fact that BCESM is specifically associated with epidemic CF strains and is rare among strains recovered from the natural environment. It has been proposed that the BCESM DNA may mark a region of the $B$. cepacia genome that encodes virulence factors or regu-

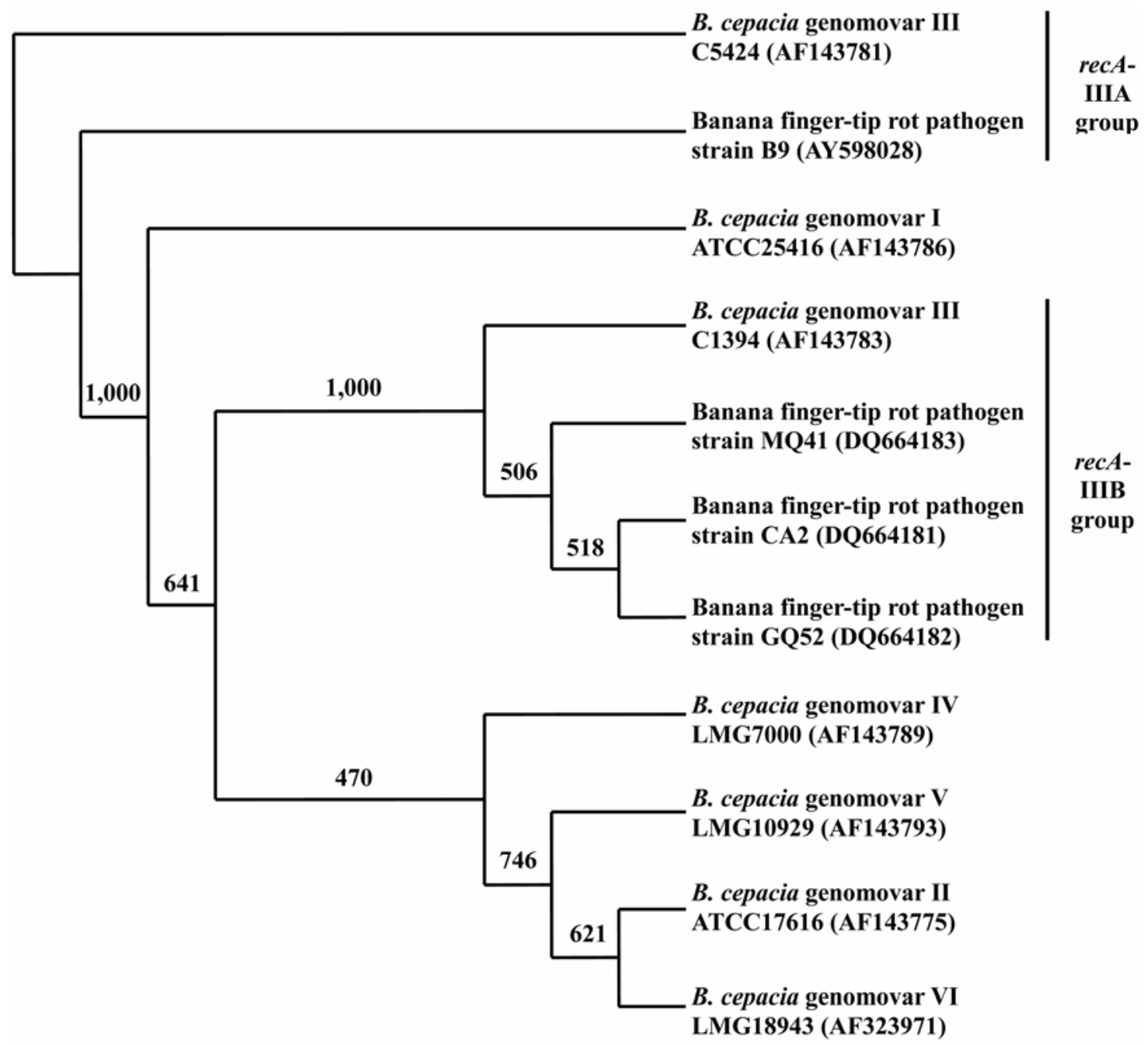

Fig. 2. Unrooted phylogenetic tree derived from neighbor-joining analysis of the recA nucleotide sequences of banana finger-tip rot pathogen strains and strains of Burkholderia cepacia genomovars. Bootstrapping resampling statistics were applied to the tree (1,000 data sets), and bootstrap values are shown on each horizontal branch of the tree. GenBank accession numbers are given in parenthesis after the bacterial names. 
lators that play a role in strain transmissibility (17). All group A and B strains from bananas contained BCESM; therefore, the better transmissibility of group B strains compared with group A strains could not be attributed to the presence of BCESM. Nevertheless, because the BCESM DNA did not hybridize to DNA from a wide variety of other microorganisms (17), the BCESM DNA can serve as an additional marker for the identification and the epidemiological studies of $B$. cenocepacia from banana in the future.

Even if B. cenocepacia strains from banana are not related to clinical strains, they still have the potential to evolve into human pathogens. Increasing knowledge of the B. cepacia complex raises important ecological issues, including the evolution of pathogenic bacteria through horizontal gene transfer. The transfer of genetic material between B. cenocepacia environmental and clinical strains is highly probable, with the subsequent emergence of a hybrid and pathogenic bacterium. Therefore, it is important that information on the distribution and PFGE profiles of B. cenocepacia strains is shared between agricultural and medical microbiologists. The PFGE profiles provided in this study will be very helpful for interlaboratory comparisons for strain identification and epidemiological tracking.
A

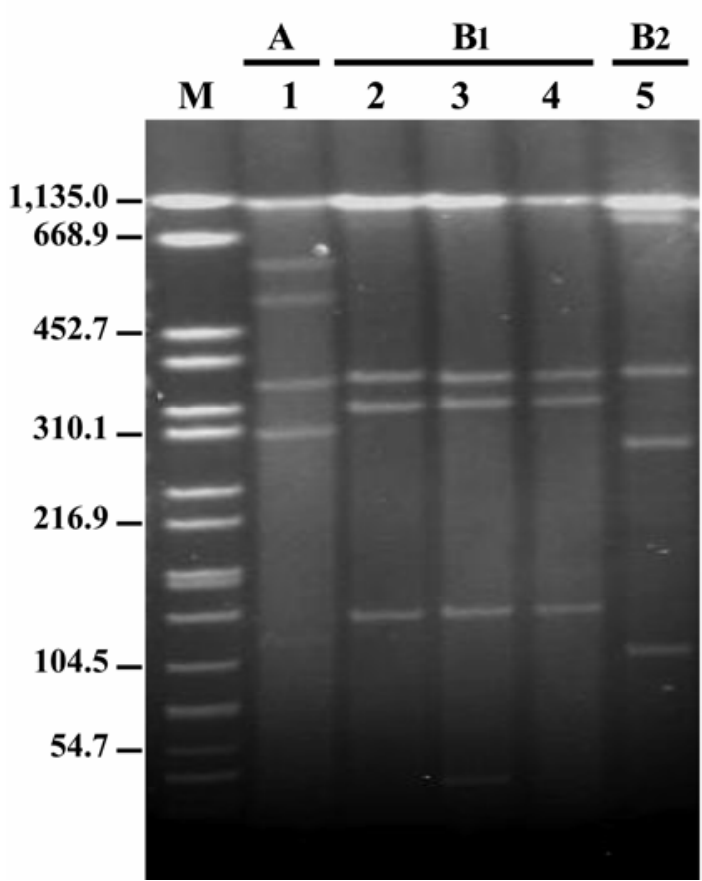

B
C

M $\frac{A}{1} \frac{B 1-1}{2} \frac{B 1-2}{34} \frac{B 2}{5} \quad M \frac{A}{1} \frac{B 1-1}{2} \frac{B 1-2-1}{3} \frac{B 1-2-2}{4} \frac{B 2}{5}$

Fig. 3. Pulsed-field gel electrophoresis (PFGE) profiles of genomic DNA from Burkholderia cenocepacia strains from banana after digestion with A, PacI, B, XbaI, or C, SpeI. Lanes 1 to 5: B. cenocepacia strains B9, CA2, GQ52, H2Q11, and MQ41, respectively. The strains were separated into two groups, A and B, corresponding to recA IIIA and B lineages. Group B strains were further separated into subgroups based on PFGE patterns. M = a PFGE profile of Salmonella strain H9812 used by PulseNet as the size standard. Numbers at the left indicate the band sizes in kilobase pairs.

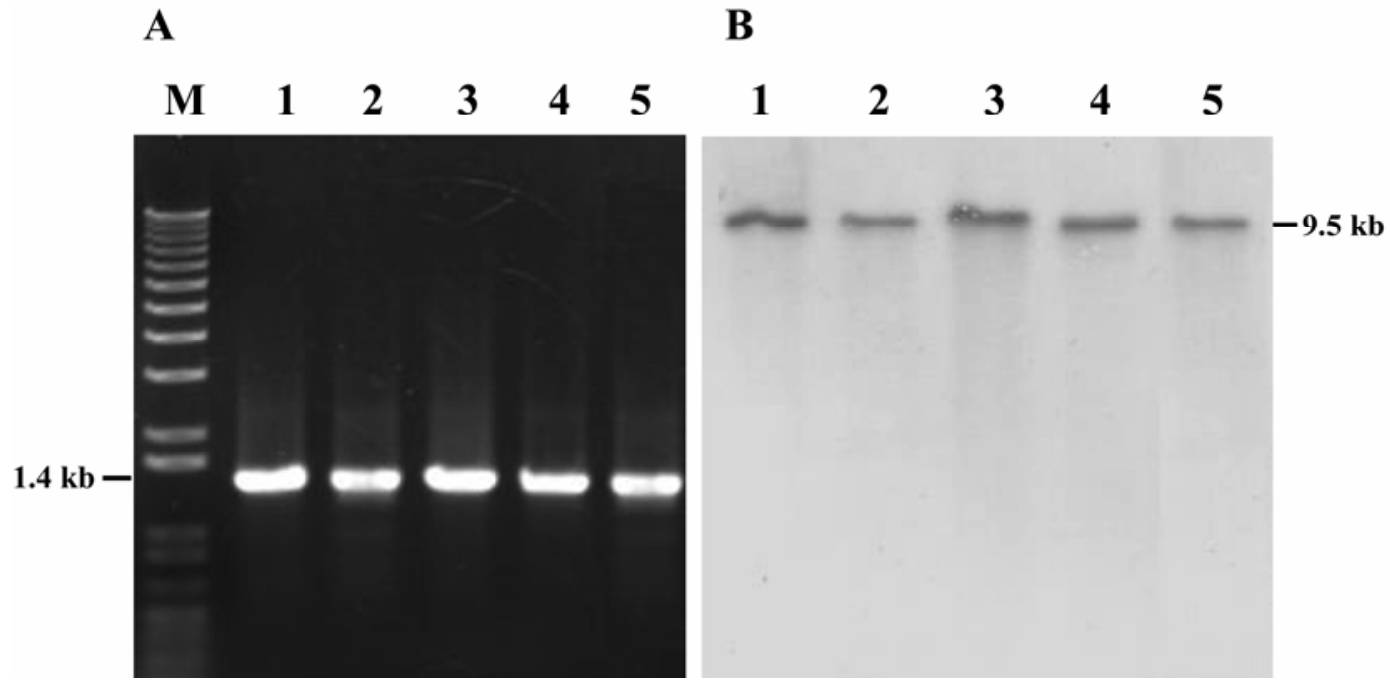

Fig. 4. Assays for the presence of Burkholderia cepacia epidemic strain marker (BCESM) in B. cenocepacia strains from banana. A, Agarose gel electrophoresis of polymerase chain reaction (PCR) products from B. cenocepacia strains using BCESM1/BCESM2 primer pairs for BCESM. B, Southern hybridization of EcoRI-digested total DNA from B. cenocepacia strains hybridized with the digoxigenin-11-dUTP-labeled PCR-amplified BCSEM DNA fragments. Lanes 1 to 5: B. cenocepacia strains B9, CA2, GQ52, H2Q11, and MQ41, respectively. M = molecular size marker (1-kb-plus DNA ladder, Gibco-BRL Life Technologies). The sizes of PCR products and hybridized bands are indicated. 
This study assessed the genetic diversity and distribution of B. cenocepacia strains from banana in southern Taiwan. The results showed that banana is a natural reservoir of genetically diversified B. cenocepacia strains. It should be emphasized, however, that although $B$. cenocepacia exists on banana in southern Taiwan, it does not indicate that the bacterium can be found on banana in other countries. A continuous epidemiological survey in other locations and countries is necessary. This study suggests that QY-TP medium and PCR assays for $b c s c V$ and BCESM DNA are highly effective for isolation, detection, and identification of B. cenocepacia from banana, and that recA PCR-RFLP and PFGE are very useful and reliable tools for further strain differentiation of B. cenocepacia in the epidemiological survey.

\section{ACKNOWLEDGMENTS}

This research was supported by grants from the Council of Agriculture (94-2101-2104-13-03-02-B1) and National Science Council Project (NSC 93-2317-B-030-001), Taiwan, Republic of China. We thank C.-P. Chao (Taiwan Banana Research Institute, Pingtung, Taiwan) for sampling the diseased banana plants with finger-tip rot, C.-S. Chiou (Center for Disease Control, Department of Health, Taiwan) for technical advice and help with the PFGE analysis, and Y.-C. Chang (Department of Plant Pathology, National Taiwan University, Taipei, Taiwan) for helpful discussions and critical reading of the manuscript.

\section{LITERATURE CITED}

1. Agodi, A., Mahenthiralingam, E., Barchitta, M., Giannino, V., Sciacca, A., and Stefani, S. 2001. Burkholderia cepacia complex infection in Italian patients with cystic fibrosis: Prevalence, epidemiology, and genomovar status. J. Clin. Microbiol. 39:2891-2896.

2. Balandreau, J., Viallard, V., Cournoyer, B., and Coenye, T. 2001. Burkholderia cepacia genomovar III is a common plant-associated bacterium. Appl. Environ. Microbiol. 67:982-985.

3. Bevivino, A., Dalmastri, C., Tabacchioni, S., Chiarini, L., Belli, M. L., Piana, S., Materazzo, A., Vandamme, P., and Manno, G. 2002. Burkholderia cepacia complex bacteria from clinical and environmental sources in Italy: Genomovar status and distribution of traits related to virulence and transmissibility. J. Clin. Microbiol. 40:846-851.

4. Butler, S. L., Doherty, C. J., Hughes, J. E., Nelson, J. W., and Govan, J. R. W. 1995. Burkholderia cepacia and cystic fibrosis: Do natural environments present a potential hazard? J. Clin. Microbiol. 33:1001-1004.

5. Coenye, T., Mahenthiralingam, E., Henry, D., LiPuma, J. J., Laevens, S., Gillis, M., Speert, D. P., and Vandamme, P. 2001. Burkholderia ambifaria sp. nov., a novel member of the Burkholderia cepacia complex including biocontrol and cystic fibrosis-related isolates. Int. J. Syst. Evol. Microbiol. 51:1481-1490.

6. Felsenstein, J. 1989. Phylip-phylogeny inference package (version 3.2). Cladistics 5:164-166.

7. Goldstein, R., Sun, L., Jiang, R.-Z., Sajjan, U. S., Forstner, J. F., and Campanelli, C. 1995. Structurally variant classes of pilus appendage fibers coexpressed from Burkholderia (Pseudomonas) cepacia. J. Bacteriol. 177:1039-1052.

8. Govan, J. R. W., and Deretic, V. 1996. Microbial pathogenesis in cystic fibrosis: Mucoid Pseudomonas aerugionosa and Burkholderia cepacia. Microbiol. Rev. 60:539-574.

9. Govan, J. R. W., Hughes, J. E., and Vandamme, P. 1996. Burkholderia cepacia: Medical, taxonomic and ecological issues. J. Med. Microbiol. 45:395-407.

10. Lee, Y.-A., Chan, C.-W., Shiao, Y.-Y., and Chao, C.-P. 2004. Determination of genomovar status of Burkholderia cepacia that causes banana finger-tip rot and development of a simple semi-selective medium for the isolation of the pathogen. Plant Pathol. Bull. (Taiwan) 13:177-184.

11. Lee, Y.-A., Shiao, Y.-Y., and Chao, C.-P. 2003. First report of Burkholderia cepacia as a pathogen of banana finger-tip rot in Taiwan. Plant Dis. 87:601.

12. LiPuma, J. J. 1998. Burkholderia cepacia-management issues and new insights. Clin. Chest Med. 19:473-486.

13. LiPuma, J. J., Spilker, T., Gill, L. H., Campbell, P. W., III, Liu, L., and Mahenthiralingam, E. 2001. Disproportionate distribution of Burkholderia cepacia complex species and transmissibility markers in cystic fibrosis. Am. J. Respir. Crit. Care Med. 164:92-96.

14. Mahenthiralingam, E., Baldwin, A., and Vandamme, P. 2002. Burkholderia cepacia complex infection in patients with cystic fibrosis. J. Med. Microbiol. 51:533-538.

15. Mahenthiralingam, E., Bischof, J., Byrne, S. K., Radomski, C., Davies, J.
E., Av-Gay, Y., and Vandamme, P. 2000. DNA-based diagnostic approaches for identification of Burkholderia cepacia complex, Burkholderia vietnamiensis, Burkholderia multivorans, Burkholderia stabilis, and Burkholderia cepacia genomovars I and III. J. Clin. Microbiol. 38:3165-3173.

16. Mahenthiralingam, E., Coenye, T., Chung, J. W., Speert, D. P., Govan, J. R., Taylor, P., and Vandamme, P. 2000. Diagnostically and experimentally useful panel of strains from the Burkholderia cepacia complex. J. Clin. Microbiol. 38:910-913.

17. Mahenthiralingam, E., Simpson, D. A., and Speert, D. P. 1997. Identification and characterization of a novel DNA marker associated with epidemic Burkholderia cepacia strains recovered from patients with cystic fibrosis. J. Clin. Microbiol. 35:808-816.

18. Parsons, Y. N., Glendinning, K. J., Thornton, V., Hales, B. A., Hart, C. A., and Winstanley, C. 2001. A putative type III secretion gene cluster is widely distributed in the Burkholderia cepacia complex but absent from genomovar I. FEMS Microbiol. Lett. 203:103-108.

19. Ribot E. M., Fitzgerald, C., Kubota, K., Swaminathan, B., and Barrett, T. J. 2001. Rapid pulsed-field gel electrophoresis protocol for subtyping of Campylobacter jejuni. J. Clin. Microbiol. 39:1889-1894.

20. Saitou, N., and Nei, M. 1987. The neighbor-joining method: A new method for reconstructing phylogenetic trees. Mol. Biol. Evol. 4:406-425.

21. Sajjan, U. S., Sun, L., Goldstein, R., and Forstner, J. F. 1995. Cable ( $\mathrm{Cbl})$ type II pili of cystic fibrosis-associated Burkholderia (Pseudomonas) cepacia: Nucleotide sequence of the cblA major subunit pilin gene and novel morphology of the assembled appendage fibers. J. Bacteriol. 177:1030-1038.

22. Sajjan, U. S., Sylvester, F. A., and Forstner, J. F. 2000. Cable-piliated Burkholderia cepacia binds to cytokeratin 13 of epithelial cells. Infect. Immun. 68:1787-1795.

23. Sambrook, J., Fritsch, E. F., and Maniatis, T. 1989. Molecular Cloning: A Laboratory Manual. 2nd ed. Cold Spring Harbor Laboratory, Cold Spring Harbor, NY.

24. Schaad, N. W., Jones, J. B., and Chun, W. 2001. Laboratory Guide for Identification of Plant Pathogenic Bacteria, 3rd ed. The American Phytopathological Society, St. Paul, MN.

25. Smith, D. L., Gumery, L. B., Smith, E. G., Stableforth, D. E., Kaufmann, M. E., and Pitt, T. L. 1993. Epidemic of Pseudomonas cepacia in an adult cystic fibrosis unit: Evidence of person-to-person transmission. J. Clin. Microbiol. 31:3017-3022.

26. Speert, D. P., Bond, M., Woodman, R. C., and Curnutte, J. T. 1994. Infection with Pseudomonas cepacia in chronic granulomatous disease: Role of nonoxidative killing by neutrophils in host defence. J. Infect. Dis. 170:1524-1531.

27. Steinbach, S., Sun, L., Jiang, R., Flume, P., Gilligan, P., Egan, T. M., and Goldstein, R. 1994. Transmissibility of Pseudomonas cepacia infection in clinic patients and lung-transplant recipients with cystic fibrosis. N. Engl. J. Med. 331:981-987.

28. Sun, L., Jiang, R. Z., Steinbach, S., Holmes, A., Campanelli, C., Forstner, J., Tan, Y., Riley, M., and Goldstein, R. 1995. The emergence of a highly transmissible lineage of cbl1 Pseudomonas (Burkholderia) cepacia causing CF centre epidemics in North America and Britain. Nat. Med. 1:661-666

29. Thompson, J. D., Higgins, D. G., and Gibson, T. J. 1994. CLUSTAL W: Improving the sensitivity of progressive multiple sequence alignment through sequence weighting, position-specific gap penalties and weight matrix choice. Nucleic Acids Res. 22:4673-4680.

30. Tyler, S. D., Rozee, K. R., and Johnson, W. M. 1996. Identification of IS1356, a new insertion sequence, and its association with IS402 in epidemic strains of Burkholderia cepacia infecting cystic fibrosis patients. J. Clin. Microbiol. 34:1610-1616.

31. Vandamme, P., Henry, D., Coenye, T., Nzula, S., Vancanneyt, M., LiPuma, J. J., Speert, D. P., Govan, J. R., and Mahenthiralingam, E. 2002. Burkholderia anthina sp. nov. and Burkholderia pyrrocinia, two additional Burkholderia cepacia complex bacteria, may confound results of new molecular diagnostic tools. FEMS Immunol. Med. Microbiol. 33:143-149.

32. Vandamme, P., Holmes, B., Coenye, T., Goris, J., Mahenthiralingam, E., LiPuma, J. J., and Govan, J. R. 2003. Burkholderia cenocepacia sp. nov.-A new twist to an old story. Res. Microbiol. 154:91-96.

33. Vandamme, P., Holmes, B., Vancanneyt, M., Coenye, T., Hoste, B., Coopman, R., Revets, H., Lauwers, S., Gillis, M., Kersters, K., and Gowan, J. R. 1997. Occurrence of multiple genomovars of Burkholderia cepacia in cystic fibrosis patients and proposal of Burkholderia multivorans sp. nov. Int. J. Syst. Bacteriol. 47:1188-1200.

34. Vandamme, P., Mahenthiralingam, E., Holmes, B., Coenye, T., Hoste, B., De Vos, P., Henry, D., and Speert, D. P. 2000. Identification and population structure of Burkholderia stabilis sp. nov. (formerly Burkholderia cepacia genomovar IV). J. Clin. Microbiol. 38:1042-1047.

35. Vermis, K., Coenye, T., LiPuma, J. J., Mahenthiralingam, E., Nelis, H. J., and Vandamme, P. 2004. Identification of Burkholderia dolosa sp. nov. (formerly Burkholderia cepacia genomovar VI). Int. J. Syst. Evol. Microbiol. 54:689-691. 